\title{
Avaliação de impactos do efluente do tratamento combinado de lixiviado de aterro de resíduos sólidos urbanos e esgoto doméstico sobre a biota aquática
}

\author{
Assessment of impacts of combined treatment \\ of solid urban waste landfill leachate and sewage on aquatic biota
}

Camille Ferreira Mannarino ${ }^{1}$

Josino Costa Moreira ${ }^{2}$

João Alberto Ferreira ${ }^{1}$

Ana Rosa Linde Arias ${ }^{2}$

${ }^{1}$ Departamento de Engenharia Sanitária e do Meio Ambiente, Faculdade de Engenharia,

Universidade do Estado do Rio de Janeiro. R. São Francisco Xavier 524, Maracanã. 20.550-900 Rio de Janeiro RJ Brasil. camille@eng.uerj.br ${ }^{2}$ Centro de Estudos da Saúde do Trabalhador e Ecologia Humana, Escola Nacional de Saúde Pública Sérgio Arouca, Fundação Oswaldo Cruz.

\begin{abstract}
The impact on tilapia fish of combined treatment of landfill leachate and domestic sewage was monitored in a waste treatment plant that operated on a pilot scale using the activated sludge process. Biomarkers of sub-lethal toxicity were used to indicate the possibility of damage to organisms due to interaction with pollutants. The concentration of metallothioneins did not indicate the increased presence of metals in fish exposed than in control groups. Acetylcholinesterase enzyme activity was inhibited in only one of the exposed groups, indicating the possible presence of organophosphate and/or carbamate pesticides in treated effluent. The PAHs used as biomarkers (naphthalene, pyrene, benzo(a)pyrene and 1-hydroxypyrene) indicated that exposed fish had a greater absorption of PAHs than control groups of fish, indicating the likely presence of these compounds in at least one of the combined treatment effluents. The frequencies of micronuclei and other erythrocytic nuclear abnormalities also indicate greater genotoxic damage in cells of organisms exposed than in control groups. The use of biomarkers proved to be important to permit an evaluation of sub-lethal damage present in organisms exposed to the pollution source studied.
\end{abstract}

Key words Leachate treatment, Ecotoxicity, Biomarkers, Tilapia fish
Resumo Foi monitorado o impacto do tratamento combinado de lixiviado e esgoto doméstico de uma estação de tratamento operando em escala piloto por processo de lodos ativados, sobre peixes do gênero Tilapia. Biomarcadores de toxicidade (concentração de metalotioneinas, atividade da acetilcolinesterase, metábolitos de HPA e presença de micronúcleos) foram utilizados na avaliação dos riscos de danos aos organismos aquáticos devido à interação com poluentes contidos nos efluentes pós-tratamento. A concentração de metalotioneínas não apresentou variação significativa entre os grupos expostos e de controle. A atividade da enzima acetilcolinesterase foi inibida em apenas um dos grupos expostos, indicando possivel presença de agentes inibidores no efluente tratado. A avaliação dos metabólitos dos HPA naftaleno, pireno, benzo(a)pireno e 1-hidroxipireno sinalizou a provável presença desses compostos em ao menos um dos afluentes do tratamento combinado. As frequências de micronúcleos e outras anormalidade nucleares eritrocitárias também apontam para maior incidência de danos genotóxicos em células dos organismos expostos do que nos controles. $O$ uso de biomarcadores mostrou-se importante para possibilitar uma avaliação de danos subletais presentes em organismos expostos à fonte de poluição estudada.

Palavras-chave Tratamento de lixiviado, Ecotoxicidade, Biomarcadores, Peixes Tilápia 


\section{Introdução}

A geração de esgotos e resíduos sólidos é inerente às sociedades organizadas. Tais dejetos, bem como seus subprodutos, precisam ser tratados para minimizar os impactos de seus descartes à saúde ambiental ${ }^{1,2}$. Geralmente, quanto maior a cidade, maior a complexidade destes rejeitos e mais oneroso se torna o tratamento desses resíduos das atividades humanas.

Esgotos domésticos são constituídos por água, em percentuais superiores a $99 \%$ da composição total, contendo geralmente baixas concentrações de material orgânico e inorgânico, dissolvido ou em suspensão, que variam em quantidade e em qualidade em função dos usos aos quais a água foi submetida. Dentre as principais substâncias orgânicas comumente encontradas nos esgotos, podem ser citados carboidratos, lignina, gorduras, sabões, detergentes, proteínas e seus produtos de decomposição, além de várias outras substâncias naturais ou sintéticas, inclusive resíduos de medicamentos ${ }^{3,4}$.

Organismos patogênicos, como vírus (enterovirus etc.), bactérias (salmonellas, coliformies, shigella, vibrio cholerae etc.), protozoários (amebas etc.) e helmintos (ascaris, schistosoma, taenia tricocefalus etc.) podem estar presentes nos esgotos domésticos e causar transtornos sob o ponto de vista da saúde pública.

Um exemplo bem conhecido de transtornos à saúde pública que podem resultar da falta de saneamento básico a é a epidemia de cólera que acometeu Londres no século XIX.

O lixiviado gerado em aterros sanitários é decorrente da percolação, através das camadas do aterro, de líquidos de origem externa (águas de chuva, escoamento superficial, águas subterrâneas e fontes), da água gerada no processo de decomposição dos resíduos orgânicos e da umidade inicial dos resíduos. No processo de percolação de líquidos através das camadas de resíduos no aterro, ocorre a solubilização de substâncias orgânicas e inorgânicas, formando um novo líquido de composição bastante variável ${ }^{5}$.

O potencial poluidor do lixiviado está ligado principalmente aos altos valores de carga orgânica que apresenta, prejudicando a fauna e a flora nesses meios. Pode ainda haver a incorporação de substâncias dissolvidas ou em suspensão cujas características tóxicas apresentem risco de contaminação para os ecossistemas locais e à saúde humana ${ }^{5}$.

Dentre estas substâncias pode-se citar aquelas consideradas como potenciais ameaças para a saúde humana, tais como o arsênico, as bifenilas, o di(2-etilhexil)ftalato, o diclorometano, o etilbenzeno, os HPA, o nonilfenol, dentre outras ${ }^{6}$.

Com a finalidade de reduzir estes riscos, o tratamento combinado de lixiviado de aterros de resíduos sólidos urbanos em estações de tratamento de esgoto domestico (ETE) tem sido utilizado em vários países. Esta é uma forma de reduzir os custos de operação dos aterros e controlar os efeitos da disposição ambiental destes resíduos. Em geral, o custo de tratamento do lixiviado quando feito isoladamente pode atingir valores bastante elevados, por requerer conjuntos usualmente complexos de operações de tratamento e por continuar a se fazer necessário mesmo após décadas de encerramento do aterro ${ }^{7-11}$.

Entretanto, se, sob o aspecto da operação dos aterros, o tratamento combinado pode ser uma solução para as dificuldades encontradas para se tratar o lixiviado, sob o das estações questionase sobre os problemas que o lixiviado pode causar nos processos de tratamento e sobre a qualidade do efluente. Estes questionamentos têm origem nas características diferenciadas que o lixiviado apresenta em relação ao esgoto, dentre as quais se encontram as elevadas concentrações de compostos orgânicos recalcitrantes, de nitrogênio amoniacal e de salinidade.

As técnicas de tratamento de efluentes mais comumente adotadas nas ETE nem sempre asseguram que o efluente seja totalmente desprovido de toxicidade, uma vez que seu controle é feito através de testes físico-químicos. Para evitar que os efluentes descartados nos corpos hídricos causem efeitos tóxicos à biota aquática e à saúde humana, de natureza aguda ou crônica, é necessário que o seu controle incorpore também a realização de bioensaios, ou seja, a avaliação de biomarcadores de toxicidade e de controle da poluição ${ }^{12-14}$.

Os bioensaios buscam identificar interações entre os poluentes presentes no ambiente e em organismos vivos por meio do uso de biomarcadores $^{15,16}$. Estes são capazes de detectar precocemente efeitos possíveis da contaminação ambiental sobre os organismos vivos antevendo possíveis impactos sobre a saúde humana. Observando alterações de funções vitais ou de composição química nos organismos, é possível se conhecer efeitos da exposição a poluentes antes que danos mais significativos possam ocorrer ${ }^{17}$.

O presente trabalho tem como objetivo apresentar os resultados da avaliação do tratamento combinado do lixiviado oriundo do Aterro de resíduos sólidos urbanos do Morro do Céu, localizado na cidade de Niterói (RJ) e de esgotos 
domésticos daquela cidade sobre alguns bioindicadores.

Este trabalho foi realizado na ETE de Icaraí, em escala piloto, e utilizou-se como organismoteste, peixes do gênero Tilápia.

\section{Materiais e métodos}

A fim de possibilitar a avaliação do tratamento combinado de lixiviado e esgoto doméstico por meio de biomarcadores, peixes conhecidos como Tilápia foram expostos ao efluente tratado de uma estação de tratamento combinado de lixiviado e esgoto operando em escala piloto.

A escolha de Tilápias como organismos-teste para o estudo deveu-se a um conjunto de fatores, quais sejam: são organismos existentes em grande parte dos corpos hídricos de água doce no território nacional, embora sejam exóticos, originários da África; apresentam grande importância comercial, pois têm lugar expressivo entre os peixes de água doce cultivados para alimentação humana; são organismos com boa capacidade de adaptação a variações de qualidade de água, quando comparados com outros peixes cultivados apresentam tolerância a baixos níveis de oxigênio dissolvido e a altas concentrações de amônia; e são capazes de se desenvolver em ampla faixa de acidez e alcalinidade na água ${ }^{18,19}$.

\section{Estação de Tratamento Combinado em Escala Piloto}

A estação de tratamento piloto foi implantada na área da Estação de Tratamento de Esgotos (ETE) Icaraí, localizada na cidade de Niterói (RJ). A estação piloto operou por processo de lodos ativados e foi projetada para tratar lixiviado de forma conjunta com esgoto doméstico em regime de aeração prolongada.

A estação de tratamento por lodos ativados em escala piloto era composta de reator aeróbio, operado com volume de $1150 \mathrm{~L}$, decantador e sistema de reciclo de lodo. A estação piloto operou com vazão média de $60 \mathrm{~L} / \mathrm{h}$ e tempo de detenção hidráulica variando entre $17 \mathrm{~h}$ e $19 \mathrm{~h}$, com recirculação do lodo biológico.

A alimentação da estação de tratamento piloto foi feita com afluente captado dentro da caixa de areia da ETE Icaraí, contendo uma mistura de esgoto doméstico com lixiviado em proporções que variaram entre $0,5 \%$ a $1 \%$. O lixiviado afluente à ETE Icaraí é proveniente do Aterro do Morro do Céu, também localizado em Niterói.
O Aterro do Morro do Céu, à época da elaboração do estudo, operava como um aterro controlado, onde eram recebidas em torno de 750 toneladas de resíduos sólidos urbanos por dia. A produção de lixiviado no aterro era de aproximadamente $150 \mathrm{~m}^{3} / \mathrm{dia}$, os quais eram encaminhados para tratamento na ETE Icaraí.

\section{Bioensaios}

Foi construído um aquário destinado a receber o efluente tratado diretamente da estação de tratamento combinado em escala piloto e a abrigar os peixes a serem avaliados. O aquário foi implantado em uma caixa d'água de 1000L, fabricada em PEAD.

Os peixes inseridos no aquário não receberam qualquer tipo de ração ou outro alimento além do efluente tratado da estação de tratamento piloto. Foram utilizados peixes machos com peso em torno de $500 \mathrm{~g}$, adquiridos vivos em criadouro, no sentido de tentar garantir a sua não contaminação inicial. Quatro compressores de ar de aquário realizaram a aeração na caixa d'água.

Foram realizados quatro experimentos de exposição dos peixes no aquário ao efluente tratado da estação piloto. O primeiro experimento teve 14 peixes expostos e duração de sete dias. $\mathrm{O}$ segundo experimento teve seis peixes expostos e duração de sete dias. O terceiro e quarto experimentos tiveram oito peixes expostos e duração de 14 dias. Nos experimentos descritos, a proporção da mistura de lixiviado na alimentação da estação piloto manteve-se entre $0,5 \%$ e $1 \%$. Todos os experimentos foram realizados entre outubro e dezembro de 2008.

Os peixes controles, não submetidos à exposição e utilizados para comparação, totalizaram 25 unidades. Estes peixes eram levados ao laboratório para coleta de amostras biológicas no mesmo dia da sua coleta no fornecedor. Não foi possível realizar ensaios controle com esgoto puro devido ao fato deste já chegar à ETE Icaraí misturado com o lixiviado. Também não foi possível manter os peixes controle em tanques alimentados com água pelos mesmos tempos de exposição em função das limitações operacionais da pesquisa.

Os biomarcadores avaliados abrangem níveis de organização individual, molecular e celular. Em nível individual, foram contabilizados o tamanho e o peso dos peixes e calculado o Fator de Condição. Em nível molecular, foram utilizadas a concentração de metalotioneínas, como biomarcadores de exposição a metais tóxicos, a 
atividade da enzima acetilcolinesterase, indicadora de efeitos neurotóxicos decorrentes da exposição a agentes inibidores tais como os agrotóxicos organofosforados e carbamatos, e a concentração de metabólitos de HPA (hidrocarbonetos policíclicos aromáticos) na bile, indicador de exposição à HPA. Em nível celular, foi realizada a contagem de micronúcleos e de outras anormalidades nucleares, como indicativos de danos ao material genético das células, representando efeitos genotóxicos aos organismos.

Os bioensaios foram realizados no Laboratório de Ecotoxicologia do Centro de Estudos em Saúde do Trabalhador e Ecologia Humana da ENSP/Fiocruz.

\section{Fator de Condição (FC)}

O Fator de Condição foi calculado por uma relação entre a média dos pesos e a média dos comprimentos dos peixes de determinado grupo amostral, por meio da fórmula $F C=$ peso $\times 100 /$ tamanho ${ }^{3}$. Os pesos dos peixes são indicados em gramas e os comprimentos em centímetros ${ }^{16,20}$.

\section{Metalotioneínas (MT)}

As avaliações de concentração de metalotioneínas foram realizadas em tecidos de fígado de peixes, seguindo o Método de Brdicka ${ }^{21}$. As amostras foram homogeneizadas em solução Tampão Tris-Sacarose (Tris - $20 \mathrm{mM}$; Sacarose - 0,5 M, pH 8,6), na razão 3:1 (volume de tampão:peso de fígado).

Para a determinação da MT, foram colocados $10 \mathrm{~mL}$ de Eletrólito (Cloreto de Hexamina Cobalto $-6 \times 10^{-4} \mathrm{M}$, Cloreto de Amônio - $1 \mathrm{M}$, Hidróxido de Amônio - 1 M, pH 9,5) em cubetas, onde foram adicionados $100 \mu \mathrm{L}$ de amostra. A quantificação da MT foi realizada polarograficamente.

\section{Acetilcolinesterase (AChE)}

As avaliações de inibição da enzima acetilcolinesterase foram realizadas em tecidos de músculo de peixes, de acordo com Oliveira-Silva et al. ${ }^{22}$ e Ellman et al. ${ }^{23}$. Os músculos foram homogeneizados em solução Tampão Fosfato de Sódio $(0,12 \mathrm{M}, \mathrm{pH} 7,6)$ na razão $1: 6$ (peso de músculo:volume de tampão).

Para a determinação da atividade da AChE, foram preparados tubos com $2 \mathrm{ml}$ de tampão Fosfato de Sódio (0,12 M, pH 7,6) e $500 \mu$ l de DTNB (2 $\mathrm{mM}$, preparado em tampão fosfato de sódio 0,12
$\mathrm{M}, \mathrm{pH} 7,6)$, onde foram adicionados $500 \mu \mathrm{l}$ de acetiltiocolina e $50 \mu \mathrm{L}$ de amostra. As absorvâncias foram deeterminadas em espectofotômetro.

A atividade específica da AChE, dada pela razão entre os valores de atividade enzimática de AChE e a respectiva concentração de proteína na amostra, foi expressa em $\mu$ moles AChE/min/mg de proteína.

\section{Hidrocarbonetos Policíclicos Aromáticos (HPA)}

Foram determinadas as concentrações de metabólitos de naftaleno, pireno, benzo(a)pireno e também o 1-hidroxipireno em bile de peixes, de acordo com os procedimentos descritos por Freire ${ }^{24}$.

Para estas determinação, as amostras foram sonicadas por 15 minutos, diluídas em água/etanol em proporção de 50:50 (volume:volume) e determinadas espectrofluorometricamente.

A presença dos metabolitos do naftaleno, pireno e benzo(a)pireno foi analisada por método de Fluorescência de Comprimento de Onda Fixo - FF e do 1-hidroxipireno, por método de Espectrometria de Fluorescência Sincronizada (SFS) ${ }^{24}$.

Determinaram-se as proteínas biliares totais e as suas concentrações, a fim de proceder a normalização pelo status alimentar.

\section{Micronúcleos (MN)}

O método para avaliação de micronúcleos consiste na contagem de células que contenham um ou mais micronúcleos citoplasmáticos. Os procedimentos de análise seguiram a descrição de Sánchez-Galán et al. ${ }^{25}$. As avaliações das contagens de micronúcleos foram realizadas em eritrócitos, coletados junto às brânquias dos peixes.

As lâminas foram sequencialmente coradas com corante de May-Grünwald por 2 minutos, corante de May-Grünwald mais água destilada em proporção de 1:1 por 3 minutos e corante Giemsa mais água destilada em proporção de 1:6 por 10 minutos. Em seguida, as lâminas foram lavadas com água destilada e secas com Eukkit.

A frequência relativa de micronúcleos foi avaliada em microscópio ótico, com capacidade de ampliação de 1000 vezes. Foram contados em média 1000 eritrócitos mononucleados por lâmina como referência.

Além de micronúcleos, foi realizada a contagem de outras anormalidades nucleares nas células analisadas, as quais foram agrupadas, para avaliação dos resultados, como "anormalidades nucleares eritrocitárias". 


\section{Análises Estatísticas}

Verificou-se a normalidade da distribuição dos dados amostrais para cada conjunto de dados avaliado, utilizando-se os testes AndersonDarling, Ryan-Joiner e Kolmogorov-Smirnov.

De acordo com a normalidade ou não da distribuição dos conjuntos de dados amostrais dos grupos comparados, foram usados os testes de análise de variância One Way ANOVA (paramétrico) e Kruskal-Wallis Test (não paramétrico). $\mathrm{Na}$ sequência, foram usados testes de comparações múltiplas (Post hoc Tests) Tukey's Test (paramétrico) e Mann-Whitney Test (não paramétrico). Todos os testes foram realizados no programa Minitab 15, com nível de confiança de 95\%.

\section{Resultados e discussão}

A caracterização do afluente e do efluente da estação de tratamento combinado em escala piloto, durante o período de realização dos bioensaios, é apresentada na Tabela 1. Percebe-se que a adição de lixiviado ao afluente da estação de tratamento não implicou em concentrações médias de matéria orgânica maiores do que o previsto nas faixas típicas para esgoto doméstico, entre 250 e $400 \mathrm{mg} /$ L de DBO e 450 e 800 mg/L de DQO. A concentração de nitrogênio amoniacal no afluente foi au-

Tabela 1. Caracterização do afluente e do efluente da estação de tratamento piloto - valores médios.

\begin{tabular}{lcc}
\hline Parâmetros & $\begin{array}{c}\text { Afluente à ETE Piloto } \\
\text { (esgoto + lixiviado) }\end{array}$ & $\begin{array}{c}\text { Efluente da } \\
\text { ETE Piloto }\end{array}$ \\
\hline $\mathrm{pH}$ & 7,5 & 7,5 \\
$\mathrm{DQO}(\mathrm{mg} / \mathrm{L})$ & 379 & 80 \\
$\mathrm{DBO}(\mathrm{mg} / \mathrm{L})$ & 243 & 43 \\
$\mathrm{SST}(\mathrm{mg} / \mathrm{L})$ & 208 & 70 \\
$\mathrm{~N}-\mathrm{NH}_{3}(\mathrm{mg} / \mathrm{L})$ & 36 & 3,2 \\
\hline
\end{tabular}

mentada, deslocando o valor médio para um pouco acima da faixa esperada para esgoto doméstico puro, $20 \mathrm{mg} / \mathrm{L}$ a $35 \mathrm{mg} / \mathrm{L}^{2}$.

Um resumo das condições de operação dos experimentos realizados é apresentado na Tabela 2 .

Os peixes que morreram durante as exposições foram descartados, sem serem considerados neste estudo. O número significativo de peixes mortos nos experimentos realizados pode estar associado ao estresse sofrido durante o transporte entre o criadouro e o local de exposição. Outro fator possível de ter contribuído para as mortes é a disputa por espaço pelos peixes confinados no aquário. Como o foco do trabalho era a avaliação dos peixes vivos, não foram feitas análises no sentido de identificar sinais que pudessem indicar as causas de suas mortes.

Durante todas as exposições realizadas, o pH no aquário manteve-se entre 6,3 e 7,0 e a concentração de oxigênio dissolvido, variando entre 4 $\mathrm{mg} / \mathrm{L}$ e $6 \mathrm{mg} / \mathrm{L}$. A temperatura da água no aquário variou entre $22^{\circ} \mathrm{C}$ e $24^{\circ} \mathrm{C}$.

Dados obtidos das exposições que operaram com a mesma faixa percentual de lixiviado na mistura de alimentação e mesmo tempo de exposição foram agrupados para avaliação. Dessa forma, os resultados foram reunidos em três grupos: Controle; Exposto 7 dias - 0,5 a 1\% lixiviado; Exposto 14 dias - 0,5 a 1\% lixiviado.

Os resultados do monitoramento dos organismos-teste para todos os biomarcadores avaliados estão apresentados na Tabela 3 e estão expressos na forma de intervalos de variação, para cada biomarcador e grupo avaliado. As letras sobrescritas que acompanham cada intervalo de variação indicam se houve ou não diferença significativa $(\alpha=0,05)$ entre os grupos, para determinado biomarcador. Assim, letras iguais indicam ausência de diferença significativa entre os grupos e letras diferentes indicam diferença significativa entre os grupos.

Análises de variância permitiram inferir que os pesos e os comprimentos médios dos peixes não apresentam diferenças estatísticas entre gru-

Tabela 2. Resumo das condições de operação dos experimentos de bioensaios.

\begin{tabular}{lcccc}
\hline Experimento & $\begin{array}{c}\text { \% de Lixiviado } \\
\text { no Afluente ao Tratamento }\end{array}$ & $\begin{array}{c}\text { Duração da Exposição } \\
\text { (dias) }\end{array}$ & $\begin{array}{c}\text { Peixes } \\
\text { Expostos }\end{array}$ & $\begin{array}{c}\text { Peixes } \\
\text { Sobreviventes }\end{array}$ \\
\hline Exposição I & 0,5 a $1 \%$ & 7 & 14 & 5 \\
Exposição II & 0,5 a $1 \%$ & 7 & 6 & 6 \\
Exposição III & 0,5 a $1 \%$ & 14 & 8 & 4 \\
Exposição IV & 0,5 a $1 \%$ & 14 & 8 & 4 \\
\hline
\end{tabular}


Tabela 3. Resultados do monitoramento dos organismos-teste para todos os biomarcadores avaliados.

\begin{tabular}{|c|c|c|c|c|}
\hline Biomarcadores & Unidade & $\begin{array}{l}\text { Grupo Controle } \\
\qquad(\mathrm{N}=27)\end{array}$ & $\begin{array}{l}\text { Exp. } 7 \text { dias; } 0,5 \\
\text { a } 1 \% \text { lixiv. } \\
\quad(\mathrm{N}=11)\end{array}$ & $\begin{array}{c}\text { Exp. } 14 \text { dias; } 0,5 \\
\text { a } 1 \% \text { lixiv. } \\
(\mathrm{N}=8)\end{array}$ \\
\hline Peso & $\mathrm{g}$ & $323,7-920,0^{a}$ & $322,7-535,0^{a}$ & $318,0-549,4^{a}$ \\
\hline Comprimento & $\mathrm{cm}$ & $24,6-31,0^{b}$ & $24,5-29,7^{b}$ & $27,1-34,0^{b}$ \\
\hline Fator de Condição & $\mathrm{g} / \mathrm{cm}^{3}$ & $1,51-2,42^{c}$ & $1,74-2,40^{c}$ & $1,22-2,06^{d}$ \\
\hline Acetilcolinesterase & $\mathrm{m}$ moles AChE $/ \mathrm{min} / \mathrm{mg}$ PTN & $0,104-0,578^{e}$ & $0,105-0,150^{f}$ & $0,141-0,257^{\mathrm{e}}$ \\
\hline Metalotioneína & $\mathrm{mg} \mathrm{MT/g} \mathrm{de} \mathrm{fígado}$ & $0,399-1,678 \mathrm{~g}$ & $0,474-1,454 \mathrm{~g}$ & $0,518-0,893 \mathrm{~g}$ \\
\hline Pireno & mg Py /mg PTN & $0,000079-0,001219^{\mathrm{h}}$ & $0,000428-0,009728^{i}$ & $0,000082-0,006672{ }^{i}$ \\
\hline Benzo(a)pireno & $\mathrm{mg} \mathrm{BaP} / \mathrm{mg} \mathrm{PTN}$ & $0,000052-0,002306^{j}$ & $0,000523-0,030001^{\mathrm{k}}$ & $0,000604-0,004719^{k}$ \\
\hline Hidroxipireno & mg ohpy /mg PTN & $0,000007-0,000319^{1}$ & $0,000079-0,004646^{\mathrm{m}}$ & $0,000037-0,001377^{m}$ \\
\hline Naftaleno & mg Naf /mg PTN & $0,002816-0,079359^{n}$ & $0,009688-0,937635^{\circ}$ & $0,007163-0,171836^{\circ}$ \\
\hline Micronúcleos & Frequência/1000 cel & $0-1^{p}$ & $0-3 q$ & $0-9 q$ \\
\hline Anorm. nucl. eritroc. & Frequência/1000 cel & $0-33^{r}$ & $2-172^{s}$ & $14-67^{s}$ \\
\hline
\end{tabular}

$\mathrm{N}$ = número de indivíduos avaliados. Para cada biomarcador, letras iguais ao lado dos intervalos de variação indicam ausência de diferença significativa entre os grupos e letras diferentes indicam diferença significativa entre os grupos.

pos. O Fator de Condição apresentou diferença estatística apenas para o grupo Exposto 14 dias - 0,5 a 1\% lixiviado, em relação aos demais. Este grupo apresentou menor valor médio de Fator de Condição, o que pode estar associado ao estresse causado pelo efluente do tratamento combinado e também à deficiência de alimento em um período mais longo de exposição.

Testes de análise de variância para concentração de metalotioneínas em tecidos de fígado de peixes permitem inferir que não há evidência estatística para afirmar que as médias amostrais dos quatro grupos avaliados são diferentes. Os testes indicam que a concentração média de Metalotioneínas por peso de fígado é estatisticamente igual nos grupos Controle; Exposto sete dias - 0,5 a 1\% lixiviado; Exposto 14 dias - 0,5 a 1\% lixiviado.

Mantida a concentração dessas proteínas no fígado dos peixes controle e expostos a concentrações de lixiviados diferentes, pode-se concluir que o lixiviado e o esgoto não contribuíram com concentrações significativas de metais a ponto de aumentar a produção de metalotioneínas nos organismos expostos.

Os valores encontrados para as médias amostrais da atividade da enzima acetilcolinesterase em tecidos de músculo de Tilápias nos grupos Controle e Exposto 14 dias - 0,5 a 1\% lixiviado não apresentam evidência estatística de serem diferentes.

O único grupo que apresentou média amostral significativamente diferente foi o exposto sete dias - 0,5 a $1 \%$ lixiviado, onde o valor da ativida- de da enzima acetilcolinesterase foi menor do que nos demais grupos. As justificativas para o grupo exposto que combina menor tempo de exposição apresentar menor atividade da enzima devem passar pela existência de maiores concentrações dos agentes inibidores de acetilcolinesterase no efluente do tratamento combinado. Maiores concentrações de agentes inibidores tais como os agrotóxicos organofosforados e/ou carbamatos no efluente tratado podem estar associadas à variação na composição do lixiviado ou do esgoto durante o período de exposição, induzida por algum descarte temporário desses poluentes na rede de esgotos ou no aterro de resíduos.

Todos os HPA (naftaleno, Pireno, benzo(a)pireno e 1-hidroxipireno) utilizados como biomarcadores seguiram o mesmo padrão de comportamento em relação às diferenças encontradas entre os grupos. A comparação entre as médias amostrais do grupo controle e os diferentes grupos expostos para cada biomarcador permite inferir que há evidência estatística de que as médias são diferentes. É possível afirmar que as concentrações médias de HPA na bile dos peixes controles são menores do que nos peixes expostos.

Ainda por meio de comparações estatísticas, há evidências para afirmar que as médias amostrais das concentrações de HPA na bile dos peixes expostos são iguais, para cada biomarcador, independentemente do tempo de exposição, nas condições do estudo.

As análises indicam que os peixes expostos tiveram maior absorção de HPA do que os con- 
troles, sinalizando a provável presença desses compostos em ao menos um dos afluentes ao tratamento combinado.

A presença de HPA em resíduos sólidos e lixiviados de aterros já havia sido constatada por Sisinno $^{14}$. No lixiviado do aterro do Morro do Céu, que contribui para a estação de tratamento combinado em avaliação, Sisinno ${ }^{14}$ identificou a presença de 17 HPA, incluindo Pireno e Benzo(a)pireno. A origem dos HPA nos lixiviados pode estar relacionada com a presença desses poluentes nos resíduos descartados nos aterros, com a queima de resíduos na área do aterro e com a deposição ou arraste de HPA presentes na atmosfera ${ }^{12}$.

Em aterros controlados e em lixões, a presença de HPA pode ser significativa visto que não há restrições aos resíduos recebidos, sendo comum nesses locais a presença de resíduos industriais. Nesses locais, a queima de resíduos também é usual, liberando HPA de origem pirogêni$\mathrm{ca}$, como pireno e benzo(a)pireno. Em todos os locais de disposição final de resíduos, sobretudo aqueles localizados em áreas intensamente urbanizadas e/ou industrializadas, a deposição ou o arraste de HPA presentes na atmosfera se faz importante visto que normalmente possuem extensa área superficial.

Por meio de análise estatística relativa à frequência de micronúcleos nas células de sangue coletado junto à brânquia das Tilápias, é possível inferir que a média amostral para esse biomarcador é menor nos peixes controles do que nos expostos. Para os grupos expostos sete dias $-0,5$ a $1 \%$ lixiviado e 14 dias - 0,5 a 1\% lixiviado, as médias amostrais da frequência de micronúcleos mostram-se estatisticamente iguais.

As respostas de frequências de outras Anormalidades Nucleares Eritrocitárias (excetuandose micronúcleos) também apontam para maiores danos genotóxicos em células de organismos expostos do que nos controles. Nos grupos expostos, as médias de frequência dessas anormalidades são estatisticamente iguais.

Maiores frequências de micronúcleos e de outras Anormalidades Nucleares Eritrocitárias nos peixes expostos do que nos controles podem estar relacionadas a efeitos da exposição à HPA bem como a outras substâncias lixiviadas. A avaliação dos HPA neste estudo indicou maiores concentrações desses compostos nos peixes expostos do que nos controles. Alguns dos HPA identificados na bile dos peixes expostos são considerados genotóxicos pelo International Agency for Research on Cancer (IARC) ${ }^{26}$ sendo o benzo(a)pireno classificado como carcinogênico e o naftaleno como possível carcinogênico para humanos.

\section{Conclusões}

O tratamento de lixiviado de aterros de resíduo sólidos urbanos combinado com esgoto doméstico pode ser uma alternativa importante para a minimização dos impactos causados pelos locais de disposição final de resíduos. O lixiviado gerado nesses locais muitas vezes não recebe qualquer tratamento ou é submetido a tratamentos ineficientes em remoção de poluentes antes de ser descartado no ambiente.

O tratamento de lixiviado em estações de tratamento de esgotos apresenta vantagens operacionais para a gestão dos locais de destino final de resíduos, pois possui baixo custo operacional se comparado a outros tratamentos aplicados a lixiviados, permite o tratamento desse efluente mesmo após o encerramento do aterro e possibilita, na maior parte dos casos, o atendimento à legislação de descarte de efluentes.

Entretanto, para que essa alternativa de tratamento seja considerada realmente adequada é preciso avaliar os impactos do efluente do tratamento combinado nos ecossistemas. Ensaios de ecotoxicidade subcrônica e crônica permitem conhecer os impactos do efluente nos organismos após longos períodos de exposição, como ocorre no ambiente.

Para avaliação da ecotoxicidade subcrônica, no estudo apresentado, foram avaliados nove biomarcadores em peixes do tipo Tilápia expostos ao efluente do tratamento combinado: Fator de Condição; concentração de metalotioneínas; atividade da acetilcolinesterase; concentração de metabólitos dos HPA: naftaleno, pireno, benzo(a)pireno e de 1-hidroxipireno; contagem de micronúcleos; contagem de outras anormalidades nucleares.

Por meio da avaliação dos biomarcadores foi possível inferir a presença de concentrações mais elevadas de HPA no efluente tratado, visto que esses compostos foram encontrados na bile dos peixes expostos em concentrações maiores do que naqueles controles. Da mesma forma, a frequência de micronúcleos e de outras anormalidades nucleares também foi maior nos peixes expostos, indicando maior genotoxicidade nesses organismos do que nos controles. Esses dois resultados podem estar interligados visto que alguns HPA possuem capacidade de causar danos 
genotóxicos ou ainda a outras substâncias genotóxicas presentes no lixiviado e não removidas.

$\mathrm{O}$ uso de um conjunto de biomarcadores, com especificidades para identificação de danos associados a poluentes distintos, mostrou-se importante para minimizar possíveis erros de interpretação decorrentes do uso de apenas um indicador e para possibilitar uma avaliação mais ampla de danos subletais presentes em organismos expostos a fontes de poluição.

De modo geral, há uma significativa diminuição da capacidade impactante do efluente do tratamento combinado quando comparado com o lixiviado bruto, mas o pequeno número de amostras e a capacidade limitada de diluição dos efluentes tratados utilizados neste trabalho fazem com que novos estudos sejam necessários para evidenciar os reais riscos à saúde ambiental resultantes e para a adoção definitiva deste tipo de tratamento.

\section{Colaboradores}

CF Mannarino, JC Moreira, JA Ferreira e ARL Arias participaram igualmente de todas as etapas de elaboração do artigo.

\section{Agradecimentos}

Os autores agradecem à FINEP, à Caixa Econômica Federal, a FAPEJ e ao CNPq pelo apoio financeiro. Esse estudo foi desenvolvido no escopo de um projeto de pesquisa integrante do Programa de Pesquisas em Saneamento Básico PROSAB 5. Agradecem à CLIN e à Águas de Niterói pelos dados fornecidos e suporte operacional; à equipe do Laboratório de Ecotoxicologia do CESTEH/ENSP/FIOCRUZ pela realização dos ensaios. 


\section{Referências}

1. Siqueira MM, Moraes MS. Saúde coletiva, resíduos sólidos urbanos e catadores de lixo. Cad Saude Colet 2009; 14(6):2115-2122.

2. Gouveia N. Resíduos sólidos urbanos: impactos socioambientais e perspectivas do manejo sustentável com inclusão social. Cad Saude Colet 2012; 17(6):1503-1510.

3. Jordão EP, Pessôa CA. Tratamento de Esgotos Domésticos. Rio de Janeiro: Associação Brasileira de Engenharia Sanitária (ABES); 2005.

4. Von Sperling M. Princípios do tratamento biológico de águas residuárias. Volume 1. Introdução à Qualidade das Águas e ao Tratamento de Esgotos. Belo Horizonte: Departamento de Engenharia Sanitária e Ambiental (UFMG); 2005.

5. Tchobanoglous G, Theisen H, Vigil SA. Integrated Solid Waste Management, Engineering Principles and Management Issues. New York: McGraw-Hill; 1993.

6. Health Protection Agency (HPA). [document na Internet]. Impact Health of emissions from Ladfill sites. [acessado em 2012 nov 07]. Disponível em: http:// www.hpa.org.uk/webc/HPAwebFile/HPAweb_C/ 1309969974126

7. Lema JM, Mendez R, Blazquez R. Characteristics of Landfill Leachates and Alternatives for Their Treatment: A Review. Water, Air, and Soil Pollution 1988; 40(3-4):223-250.

8. Diamadopoulos E, Samaras P, Dabou X, Sakellaropoulos GP. Combined Treatment of Landfill Leachate and Domestic Sewage in a Sequencing Batch Reactor. Water Science \& Technology 1997; 36(2-3):6168.

9. Ebert R. Estudo de Regulamentos para Recebimento de Efluentes Não Domésticos no Sistema Público de Esgotos. In: Anais do $20^{\circ}$ Congresso Brasileiro de Engenharia Sanitária e Ambiental; 1999; Rio de Janeiro. Rio de Janeiro: Associação Brasileira de Engenharia Sanitária e Ambiental; 1999.

10. Ehrig HJ. Co-treatment in Domestic Sewage Facilities. In: Proceedings of International Training Seminar: Management and Treatment of MSW Landfill Leachate; 1998; Venice,Cagliari (Italy): CISA - Sanitary Environmental Engineering Centre;1998. p. XI1 a XI-10.

11. Marttinen SK Kettunen RH, Rintala JA. Occurrence and Removal of Organic Pollutants in Sewages and Landfill Leachates. Sci Total Environ 2003; 301(13):1-12.

12. Rutherford LA, Matthews SL, Doe KG, Julien GRL. Aquatic Toxicity and Environmental Impact of Leachate Discharges from a Municipal Landfill. Water Qual. Res. J. Canada 2000; 35(1):39-57.

13. Silva AC. Tratamento do Percolado de Aterro Sanitário e Avaliação da Toxicidade do Efluente Bruto e Tratado [dissertação]. Rio de Janeiro; UFRJ; 2002.

14. Sisinno CLS. Destino dos Resíduos Sólidos Urbanos e Industriais no Estado do Rio de Janeiro: Avaliação da Toxicidade dos Resíduos e suas Implicações para o Ambiente e para a Saúde Humana [tese]. Rio de Janeiro: Fiocruz; 2002.
15. Arias ARL, Inacio AF, Novo LA, Albuquerque C, Moreira JC. Multibiomarker approach in fish to assess the impact of pollution in a large Brazilian river, Paraiba do Sul. Environ Pollut 2008; 156(3):974-979.

16. Arias ARL, Inacio AF, Albuquerque C, Freire MM, Moreira JC. Biomarkers in an invasive fish species, Oreochromis niloticus, to assess the effects of pollution in a highly degraded Brazilian River. Sci Total Environ 2008; 399(1-3):186-192.

17. Arias ARL, Inacio AF, Novo LA, Viana TAP, Albuquerque C. Utilização de Biomarcadores como Ferramenta de Monitoramento e Avaliação Ambiental: O Caso de Recursos Hídricos. Mundo e Vida 2005; 6:34-41.

18. Santos ES, Neto MF, Mota S, Santos A, Aquino MD. Cultivo de Tilápia do Nilo em Esgoto Doméstico. Rev DAE 2009; 180:4-11.

19. Soares C. Análise das Implicações Sociais, Econômicas e Ambientais Relacionadas ao Uso da Piscicultura - O Caso Fazenda Princesa do Sertão - Palhoça/Sc [dissertação]. Florianópolis: UFSC; 2003.

20. Freire MM, Santos VG, Ginuino ISF, Arias ARL. Biomarcadores na Avaliação da Saúde Ambiental dos Ecossistemas Aquáticos. Oecol Bras 2008; 12(3):347-354.

21. Raspor B. Elucidation of the Mechanism of the Brdièka Reaction. Journal of Electroanalytical Chemistry 2001; 503(1-2):159-162.

22. Oliveira-Silva JJ, Alves SR, Inacio AF, Meyer A, Sarcinelli PN, Mattos RC, Ferreira MF, Cunha JC, Moreira JC. Cholinesterase Activities Determination in Froozen Blood Samples: an Improvement to the Occupational Monitoring in Developing Countries. Hum Exp Toxicol 2000; 19(3):173-177.

23. Elmann GL, Courtney K, Andres Junior A, Featherstone R. A New and Rapid Colorimetric Determination of Acetylcholinesterase Activity. Biochem Pharmacol 1961; 7:89-95.

24. Freire MM. Determinação de Metabólitos de Hidrocarbonetos Policíclicos Aromáticos em Biles de Peixes como Biomarcador na Baía De Guanabara [dissertação]. Rio de Janeiro: Fiocruz; 2008.

25. Sánchez-Galán S, Linde AR, Izquierdo JI, GarcíaVázquez E. Micronuclei and fluctuating asymmetry in brown trout (Salmo trutta): complementary methods to biomonitor freshwater ecosystems. Mutat Res 1998; 412(3):219-225.

26. International Agency for Research on Cancer (IARC). Agents Classified by the IARC Monographs, Volumes 1-100. [documento na Internet]. [acessado em 2010 jun 26]. Disponível em: http://monographs.iarc.fr/ ENG/Classification/index.php

Artigo apresentado em 09/11/2012

Aprovado em 10/01/2013

Versão final apresentada em 16/01/2013 
